\title{
Is it possible? Invasion of the heart with hepatocellular carcinoma in a short time
}

\author{
Omer Senarslan ${ }^{\mathrm{a}, *}$, Umut Hasan Kantarci ${ }^{\mathrm{b}}$, Mehmet Eyuboglu ${ }^{\mathrm{c}}$, Dilsad Amanvermez Senarslan ${ }^{\mathrm{d}}$ \\ a Department of Cardiology, Medifema Hospital, Izmir, Turkey \\ b Department of Radiology, Izmir Esrefpasa Hospital, Izmir, Turkey \\ c Department of Cardiology, Special Izmir Avrupa Medicine Center, Karabaglar, Izmir, Turkey \\ d Department of Cardiovascular Surgery, School of Medicine, Celal Bayar University, Manisa, Turkey
}

\section{A R T I C L E I N F O}

\section{Article history:}

Received 10 April 2016

Received in revised form 1 June 2016

Accepted 2 June 2016

Available online 8 June 2016

\section{Keywords:}

Hepatocellular carcinoma

Intra-cardiac mass

Transthoracic echocardiography

\begin{abstract}
A B S T R A C T
Primary and secondary cardiac tumors are a very rare entity, but secondary heart tumors are more common. Cardiac metastases occur in $10 \%$ all cancer patients. Hepatocellular carcinoma (HCC) is a very aggressive tumor. Intra-cardiac involvement with HCC rarely develops in a patient with HCC, and it has very poor prognosis. The clinical course of these patients may be complicated by many fatal cardiovascular complications. After the diagnosis of the heart involvement, median survival range is 1-4 months. Early diagnosis of cardiac involvement is very important and its easy way is performing echocardiography. We describe here a rare case of a 65-year-old man with HCC that invaded the heart in 3 months.

(C) 2016 The Society of Cardiovascular Academy. Production and hosting by Elsevier B.V. All rights reserved. This is an open access article under the CC BY-NC-ND license (http://creativecommons.org/licenses/by-nc-nd/4.0/).
\end{abstract}

\section{Introduction}

Cardiac tumors are very rare entity. ${ }^{1}$ In contrast to primary malignant cardiac tumors, metastatic involvement of the heart is relatively common. Malignant melanomas are likely to metastasize to the heart. Other solid tumors commonly associated with cardiac involvement include lung cancer, breast cancer, soft tissue sarcomas, renal carcinoma, esophageal cancer, hepatocellular carcinoma, and thyroid cancer. ${ }^{2}$ Cardiac involvement with other tumors may arise from hematogenous metastases, direct invasion from the mediastinum, or tumor growth into the vena cava and extension into the right atrium (RA). ${ }^{3}$ Primary hepatocellular carcinoma (HCC) is the fifth most common cancer worldwide and the third-leading cause of cancer-related death. ${ }^{4,5}$ HCC metastases tend to spread through intrahepatic blood vessels, lymphatics, or direct infiltration. HCCs frequently invade the vascular system at points such as the portal and hepatic veins. Intra-cardiac involvement of HCC rarely develops and the main mechanism of metastasis into the cardiac cavity is direct extension the tumor to the heart via hepatic vein and vena cava inferior. ${ }^{2}$ The results of autopsy studies indicate a $2.7-4.1 \%$ incidence of atrial metastases of HCC. $^{6}$ A correct diagnosis is important in the clinical setting since cardiac metastases are able to induce sudden cardiac arrest.

\footnotetext{
* Corresponding author at: Department of Cardiology, Medifema Hospital, Mustafa Kemal Paşa, Kocatepe Cd. No:1, 35860 Torbalı/Izmir, Turkey. Tel./fax: +902328541854. E-mail address: dromersen@yahoo.com (O. Senarslan).

Peer review under responsibility of The Society of Cardiovascular Academy.
}

\section{Case report}

A 65-year-old man with a history of hepatocellular carcinoma for 1 year presented to the cardiology clinic for dyspnea and new onset bilateral lower extremity edema rapidly progressing over 2 weeks. The diagnosis was made by hepatic biopsy and he was followed by medical oncology for 1 year with the treatment of sorafenib (multikinase inhibitor).

On physical examination, the heart rhythm was sinus, 2/6 systolic murmur in cardiac auscultation. There was pitting edema in lower extremities bilaterally and approximately $10 \mathrm{~cm}$ palpable mass at right upper quadrant of the abdomen.

2-D transthoracic echocardiography demonstrated a large mass in the right atrium extending to the tricuspid valve without significant obstruction (Fig. 1). Thoracic and upper abdominal computer tomography (CT) showed expansile liver mass with the extension of the tumor into the right atrium via invasion of the inferior vena cava (Fig. 2).

Compared with the previous CT and echocardiography images made 3 months ago, the hepatic mass of the liver was smaller and there was no VCI or intra-cardiac extension of HCC (Fig. 2). During this 3 months the liver mass got enlarged and invaded inferior vena cava thus reached the RA.

The patient was followed up conservatively because of the endstaged metastatic HCC and high mortality risk of the heart surgery. He died in 76 days after the diagnosis of intra-cardiac tumor because of liver and multi-organ failure. We did not identify left ventricular systolic failure during this follow-up time. 


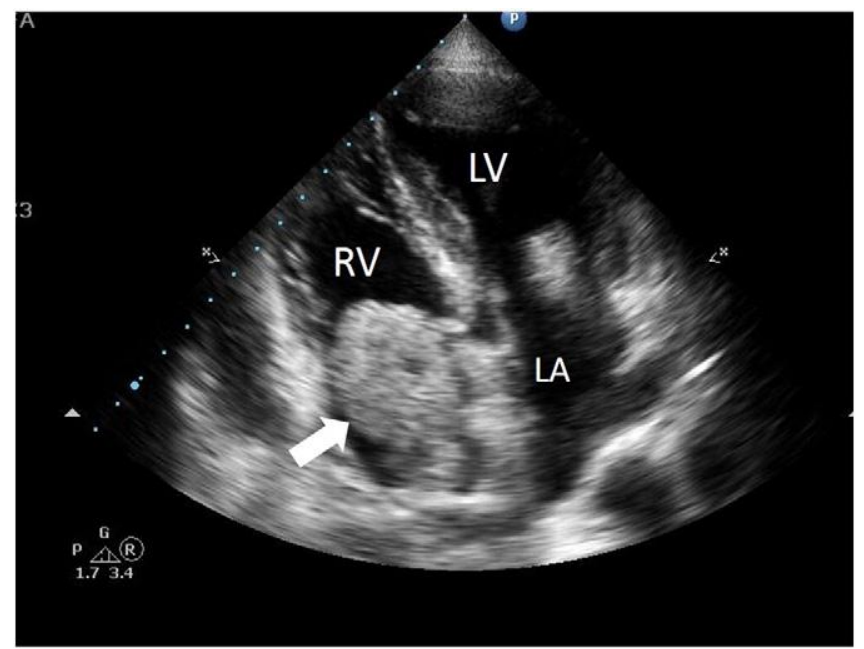

Fig. 1.2-D and color Doppler transthoracic echocardiography in apical four chamber view. Echocardiography demonstrated a huge mobile mass that fills all the right atrium space (arrow). The mass was very mobile and protruding into the RV. LV, left ventricle; LA, left atrium; RV, right ventricle.

\section{Discussion}

The majority of HCC arises from viral hepatitis. Intra-cardiac involvement rarely occurs in patients with HCC, and its frequency was found around $2 \%$ in various series. ${ }^{7}$ A literature search for case reports was performed on PubMed. We found 28 case reports or literature reviews of HCC with cardiac involvement that were published in the literature. Most of the cardiac metastases are direct and contiguous extensions of the intrahepatic HCC via hepatic vein and inferior vena cava. ${ }^{8}$ Various cardiac symptoms or findings such as dyspnea, lower extremity edema, sudden death, or dilatation of the jugular veins are generally seen in HCC patients with intra-cardiac involvement. ${ }^{1,7}$ Echocardiography is widely available and provides a simple, noninvasive technique for the initial evaluation of cardiac involvement of any tumor. Echocardiography images both the myocardium and the cardiac chambers and can usually identify the presence of a mass, its mobility and its functional effects. Both computed tomography (CT) and magnetic resonance imaging (MRI) provide noninvasive, high-resolution images of the heart and the liver, MRI generally is preferred. In addition to furnishing detailed anatomic images, MRI offers clues as to the type of tumor that is present. ${ }^{9}$ However, CT scanning is still useful when MRI is not immediately available or is contraindicated.

The prognosis of HCC with intra-cardiac involvement is very poor, with a median survival range of 1-4 months. ${ }^{10}$ The risk for cardiopulmonary collapse is high in such patients. Possible cardiopulmonary complications include heart failure, tricuspid stenosis or insufficiency, ventricular outflow tract obstruction, sudden cardiac death, pulmonary embolism, and pulmonary metastasis. ${ }^{8}$ Multidisciplinary treatments to control the growth of HCC and cardiac surgery in young patients offer patients with cardiac involvement a useful chance of cure. However, such therapeutic modalities may not be feasible, especially if the patient has a poor general performance, metastatic disease, or underlying hepatic dysfunction. ${ }^{10} \mathrm{~A}$ cardiac surgery for cardiac involvement of HCC to remove the mass can have high mortality.

This case report showed that intrahepatic HCC can disseminate and invade the heart in a short time. Even there are no curative treatments for metastatic HCC, following these patients with echocardiography periodically may give notice about cardiac involvement. We want to emphasize the importance of monitoring the patient with HCC by echocardiography with short time intervals not only for side effects of chemotherapy, but also to detect heart involvement of HCC.

\section{Disclosures}

The authors have no conflicts of interest to disclose.

\section{References}

1. Yusuf SW, Bathina JD, Qureshi S, et al. Cardiac tumors in a tertiary care cancer hospital: clinical features, echocardiographic findings, treatment and outcomes. Heart Int 2012 Feb 3;7(1)e4 [PubMed PMID: 22690297. Pubmed Central PMCID: 3366300].

2. Goldberg AD, Blankstein R, Padera RF. Tumors metastatic to the heart. Circulation 2013 Oct 15:128(16):1790-1794 [PubMed PMID: 24126323].

3. Longo R, Mocini D, Santini M, et al. Unusual sites of metastatic malignancy: case 1 . Cardiac metastasis in hepatocellular carcinoma. J Clin Oncol Off J Am Soc Clin Oncol 2004 Dec 15;22(24):5012-5014 [PubMed PMID: 15611516].

4. Gomaa AI, Khan SA, Toledano MB, Waked I, Taylor-Robinson SD. Hepatocellular carcinoma: epidemiology, risk factors and pathogenesis. World J Gastroenterol 2008 Jul 21;14(27):4300-4308 [PubMed PMID: 18666317. Pubmed Central PMCID: 2731180].

5. Caldwell S, Park SH. The epidemiology of hepatocellular cancer: from the perspectives of public health problem to tumor biology. J Gastroenterol 2009;44(suppl 19): 96-101 [PubMed PMID: 19148801].

6. Kojiro M, Nakahara H, Sugihara S, Murakami T, Nakashima T, Kawasaki H. Hepatocellular carcinoma with intra-atrial tumor growth. A clinicopathologic study of 18
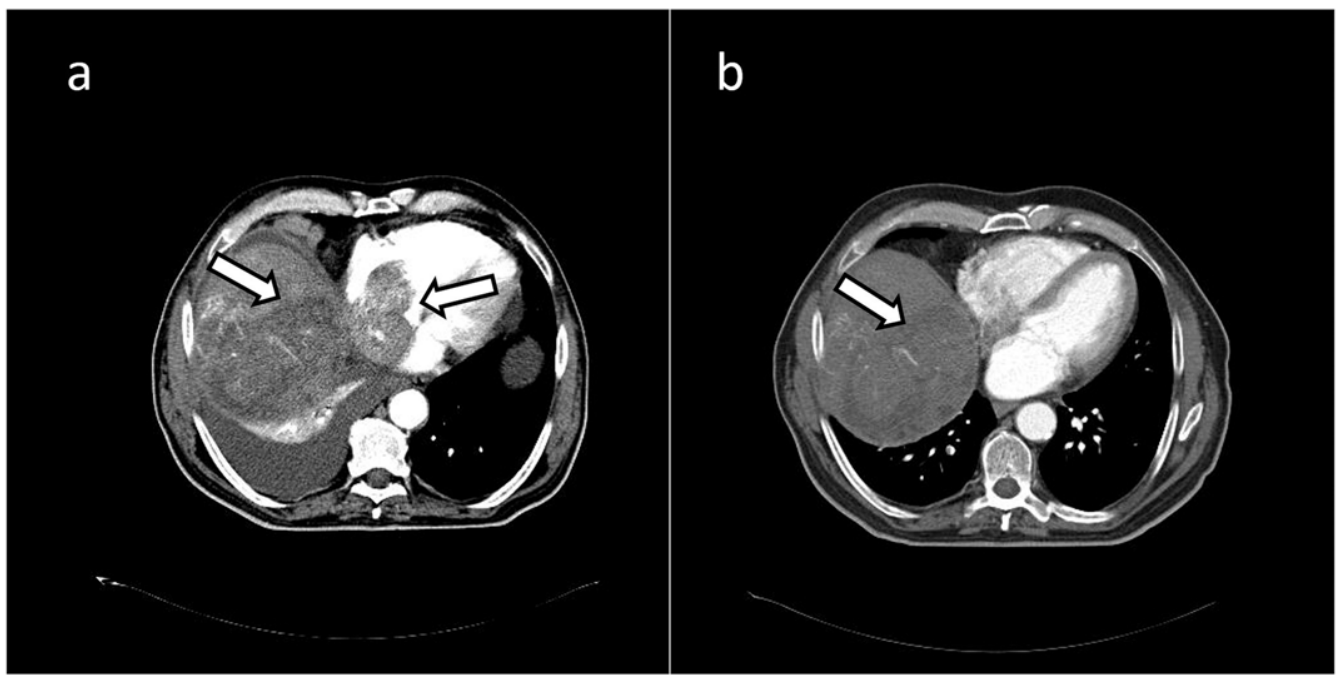

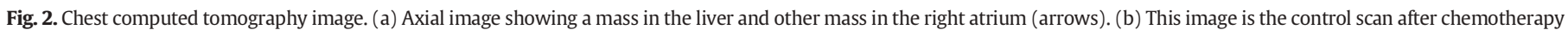

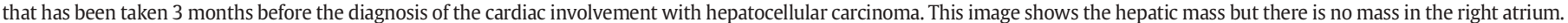


autopsy cases. Arch Pathol Lab Med 1984 Dec;108(12):989-992 [PubMed PMID: 6095786].

7. Yu K, Liu Y, Wang H, Hu S, Long C. Epidemiological and pathological characteristics of cardiac tumors: a clinical study of 242 cases. Interact Cardiovasc Thorac Surg 2007 Oct;6(5):636-639 [PubMed PMID: 17670730].

8. Sung AD, Cheng S, Moslehi J, Scully EP, Prior JM, Loscalzo J. Hepatocellular carcinoma with intracavitary cardiac involvement: a case report and review of the literature. Am J Cardiol 2008 Sep 1;102(5):643-645 [PubMed PMID: 18721529].
9. Gulati G, Sharma S, Kothari SS, Juneja R, Saxena A, Talwar KK. Comparison of echo and MRI in the imaging evaluation of intracardiac masses. Cardiovasc Intervent Radiol 2004 Sep-Oct;27(5):459-469 [PubMed PMID: 15383848].

10. Chang JY, Ka WS, Chao TY, Liu TW, Chuang TR, Chen LT. Hepatocellular carcinoma with intra-atrial tumor thrombi. A report of three cases responsive to thalidomide treatment and literature review. Oncology 2004;67(3-4):320-326 [PubMed PMID: 15557794]. 